\title{
Accuracy of electrocardiographic criteria for atrial enlargement: validation with cardiovascular magnetic resonance Connie W Tsao ${ }^{1}$, Mark E Josephson ${ }^{1}$, Thomas H Hauser ${ }^{1}$, T David O'Halloran ${ }^{1}$, Anupam Agarwal1,2, Warren J Manning1,3 and Susan B Yeon*1
} \author{
and Harvard Medical School, 330 Brookline Avenue, Boston, Massachusetts, USA \\ Email: Connie W Tsao - ctsao1@bidmc.harvard.edu; Mark E Josephson - mjoseph2@bidmc.harvard.edu; \\ Thomas H Hauser - thauser@bidmc.harvard.edu; T David O'Halloran - dtohallo@bidmc.harvard.edu; \\ Anupam Agarwal - anupam.2.agarwal@gsk.com; Warren J Manning - wmanning@bidmc.harvard.edu; \\ Susan B Yeon* - syeon@bidmc.harvard.edu \\ * Corresponding author
}

Address: ${ }^{1}$ Harvard-Thorndike Laboratory and the Department of Medicine, Cardiovascular Division, Beth Israel Deaconess Medical Center and Harvard Medical School, 330 Brookline Avenue, Boston, Massachusetts, USA, ${ }^{2}$ Cardiovascular and Metabolic Division, GlaxoSmithKline Pharmaceuticals, 1250 Collegeville Road, Collegeville, Pennsylvania, USA and ${ }^{3}$ Department of Radiology, Beth Israel Deaconess Medical Center

Published: 25 January 2008

Journal of Cardiovascular Magnetic Resonance 2008, 10:7 doi:10.1 186/1532-429X-10-7

This article is available from: http://www.jcmr-online.com/content//0/I/7

(c) 2008 Tsao et al; licensee BioMed Central Ltd.

This is an Open Access article distributed under the terms of the Creative Commons Attribution License (http://creativecommons.org/licenses/by/2.0), which permits unrestricted use, distribution, and reproduction in any medium, provided the original work is properly cited.
Received: 18 December 2007

Accepted: 25 January 2008

\begin{abstract}
Background: Anatomic atrial enlargement is associated with significant morbidity and mortality. However, atrial enlargement may not correlate with clinical measures such as electrocardiographic (ECG) criteria. Past studies correlating ECG criteria with anatomic measures mainly used inferior M-mode or two-dimensional echocardiographic data. We sought to determine the accuracy of the ECG to predict anatomic atrial enlargement as determined by volumetric cardiovascular magnetic resonance (CMR).
\end{abstract}

Methods: ECG criteria for left (LAE) and right atrial enlargement (RAE) were compared to CMR atrial volume index measurements for 275 consecutive subjects referred for CMR (67\% males, 5 I \pm 14 years). ECG criteria for LAE and RAE were assessed by an expert observer blinded to CMR data. Atrial volume index was computed using the biplane area-length method.

Results: The prevalence of CMR LAE and RAE was $28 \%$ and II\%, respectively, and by any ECG criteria was $82 \%$ and $5 \%$, respectively. Though nonspecific, the presence of at least one ECG criteria for LAE was $90 \%$ sensitive for CMR LAE. The individual criteria $\mathrm{P}$ mitrale, $\mathrm{P}$ wave axis < $30^{\circ}$, and negative $\mathrm{P}$ terminal force in $\mathrm{VI}(\mathrm{NPTF}-\mathrm{VI})>0.04 \mathrm{~s} \cdot \mathrm{mm}$ were $88-99 \%$ specific although not sensitive for CMR LAE. ECG was insensitive but $96-100 \%$ specific for CMR RAE.

Conclusion: The presence of at least one ECG criteria for LAE is sensitive but not specific for anatomic LAE. Individual criteria for LAE, including $\mathrm{P}$ mitrale, $\mathrm{P}$ wave axis $<30^{\circ}$, or NPTF-VI $>$ $0.04 \mathrm{~s} \cdot \mathrm{mm}$ are highly specific, though not sensitive. ECG is highly specific but insensitive for RAE. Individual ECG $P$ wave changes do not reliably both detect and predict anatomic atrial enlargement. 


\section{Introduction}

Atrial enlargement is a marker of increased cardiovascular events. Anatomic left atrial (LA) enlargement (LAE) is a marker of left ventricular (LV) diastolic dysfunction [1] and is associated with an abnormal stress test in subjects with known or suspected coronary artery disease [2]. In addition, it is a predictor for the development of atrial fibrillation [3-6], congestive heart failure [6], stroke [7], increased cardiac mortality $[7,8]$, incidence and survival after myocardial infarction [9-11], and combined cardiovascular events $[10,12]$. Right atrial (RA) enlargement (RAE) is associated with increased risk for congestive heart failure [13] and increased mortality in patients with primary pulmonary hypertension [14].

The electrocardiogram (ECG) is used ubiquitously in clinical practice to evaluate patients with cardiac disease. ECG criteria for atrial enlargement have shown poor sensitivity and moderate specificity for detecting enlargement as defined by two-dimensional echocardiography parasternal long axis (PLAX) and four-chamber $(4 \mathrm{Ch})$ measurements [15-23]. However, echocardiographic measures are subject to error due to variability in acquisition of appropriately aligned images, limitations in acoustic windows, and other causes of technical variation. In addition, because the LA is not a sphere with a constant radius [24], uni- or two- dimensional (2-D) echocardiographic measurements may not reflect true chamber size. Cardiovascular magnetic resonance (CMR) imaging can provide images in standardized planes, thereby providing more precise volumetric assessment of cardiac chamber size. We sought to determine the accuracy of the ECG for detection of atrial enlargement (AE) using the gold standard of volumetric CMR.

\section{Methods \\ Study population}

The study population consisted of 275 consecutive subjects referred for CMR either for clinical $(n=255)$ or research $(\mathrm{n}=20)$ purposes, between February 2001 and July 2004. Clinical CMR indications included evaluation for the following: left ventricular function ( $\mathrm{n}=111)$, pulmonary veins $(n=74)$, coronary arteries $(n=47)$, perfusion and/or viability $(\mathrm{n}=43)$, cardiomyopathy $(\mathrm{n}=38)$, intracardiac shunt $(n=4)$, valvular function $(n=3)$, pericardium $(\mathrm{n}=2)$, myocarditis $(\mathrm{n}=1)$, and cardiac mass ( $\mathrm{n}$ $=1$ ). Many subjects were referred for more than one indication. Subjects were excluded if no sinus rhythm ECG was available (see below). Age, gender, height, weight, as well as history of atrial fibrillation (AF) and hypertension were recorded. Research subjects gave informed consent according to a protocol approved by the hospital institutional review board.

\section{Electrocardiography}

A standard 12-lead ECG was performed on the same day of the CMR in all subjects in sinus rhythm $(n=201)$. An ECG in sinus rhythm, no more than 35 days from the CMR scan and prior to any pulmonary vein ablation procedures, was obtained for subjects with AF $(n=74)$. ECG LAE was defined by any one of the following: 1) $P$ wave in any lead $>0.11 \mathrm{~s}, 2)$ Notched $P$ wave with interpeak duration $>0.04 \mathrm{~s}$ (P mitrale), 3) $\mathrm{P}$ wave axis $\left.<30^{\circ}, 4\right)$ Area of negative $\mathrm{P}$ terminal force in lead V1 (NPTF-V1) > $0.04 \mathrm{~s} \cdot \mathrm{mm}$, or 5) Positive P terminal force in aVL (PPTF$\mathrm{aVL})>0.5 \mathrm{~mm}[16,18,23,25]$. ECG RAE included 1) $\mathrm{P}$ wave in inferior leads II, III, aVF $>2.5 \mathrm{~mm}$ or 2) Positive $\mathrm{P}$ wave in V1 > $1.5 \mathrm{~mm}[26,27]$. All ECG determinations were made by one experienced observer (MEJ) blinded to other results.

\section{CMR technique}

CMR was performed on a $1.5 \mathrm{~T}$ whole-body scanner (Gyroscan NT, Philips Medical Systems, NL). Among subjects with $\mathrm{AF}$, the CMR scan was performed prior to any pulmonary vein isolation procedure. Participants were imaged in the supine position with a phased-array fiveelement cardiac synergy coil for radiofrequency signal reception. Localizing scans were followed by free-breathing axial spin-echo (repetition time $800 \mathrm{~ms}$, echo time 20 $\mathrm{ms}$, field of view $300 \mathrm{~mm}$, matrix size $192 \times 512$, slice thickness $6 \mathrm{~mm}, 0.5 \mathrm{~mm}$ gap) and end-expiratory, breathhold, ECG-gated SSFP acquisitions (temporal resolution $33 \mathrm{~ms}$, repetition time $3.1 \mathrm{~ms}$, echo time $1.6 \mathrm{~ms}$, flip angle 60 degrees, field of view $400 \mathrm{~mm}$, matrix size $208 \times 256$, slice thickness $10 \mathrm{~mm}$, gap $=0$ ).

\section{Image analysis}

CMR analyses were performed using dedicated software (EasyVision 5.1, Philips Medical Systems, Best, NL). LA length was measured from the posterior wall to the plane of the mitral annulus, parallel to the long-axis of the heart, in the two-chamber $(2 \mathrm{Ch})$ and four-chamber $(4 \mathrm{Ch})$ orientations on cine SSFP acquisitions at maximum atrial diastole (Figure 1A, B). Maximum atrial diastole was defined as the image immediately preceding the opening of the mitral and tricuspid valves. Similarly, RA length was measured from the posterior wall of the RA to the plane of the tricuspid annulus in the $4 \mathrm{Ch}$ orientation (Figure 1B). LA area in apical $2 \mathrm{Ch}$ and $4 \mathrm{Ch}$ orientation were planimetered by tracing the endocardial border in maximum atrial diastole, excluding the confluence of the pulmonary veins and LA appendage (Figure 1C, D). Similarly, the 4 Ch RA area was planimetered, excluding the confluence of the vena cavae and the atrial appendage (Figure 1D). The borders of the atria were delimited at the planes of the AV annulus and the junctions of venous inflow. Atrial volumes were calculated according to the biplane area-length method, then indexed for body surface area (BSA) [28- 


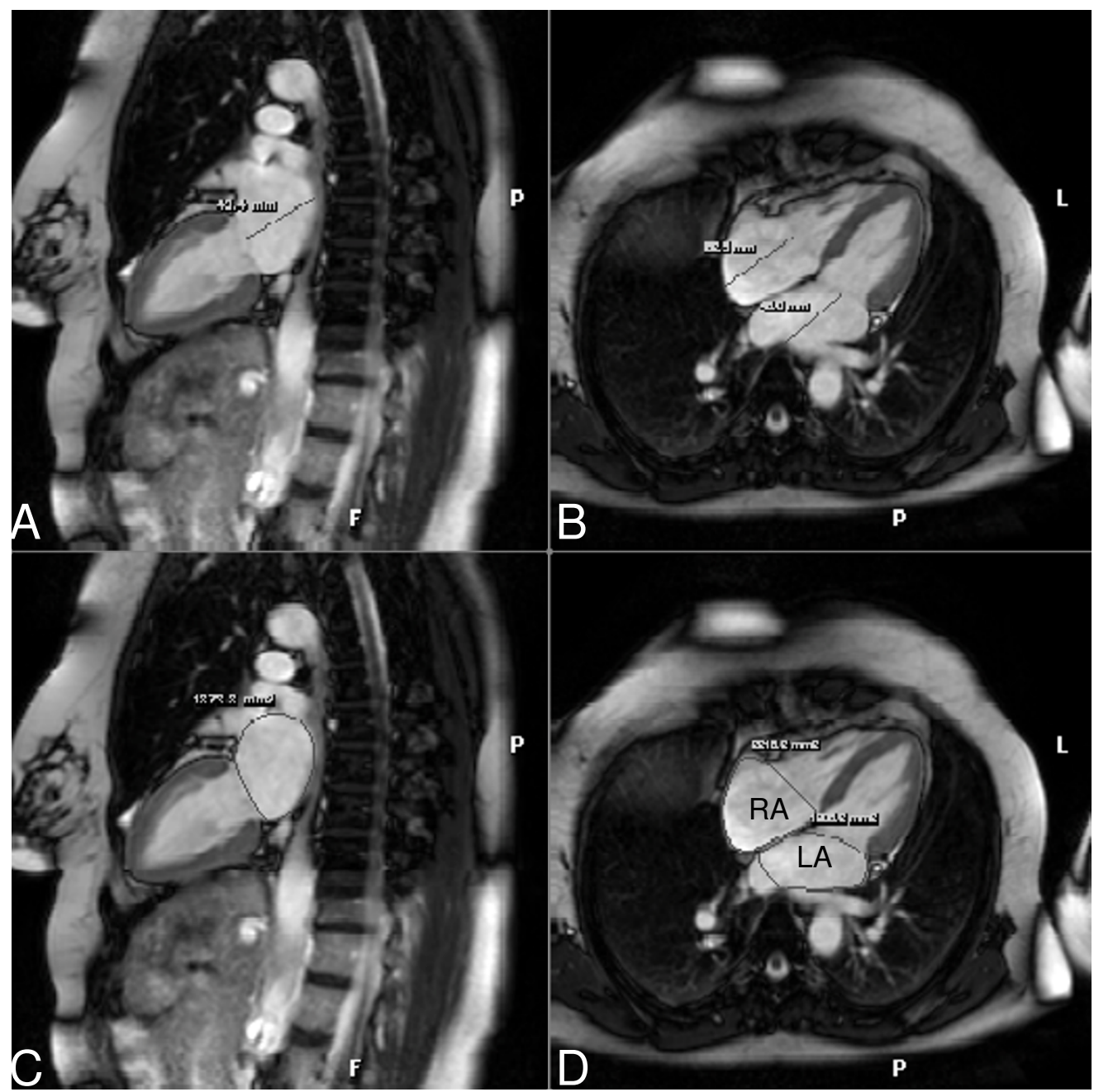

Figure I

CMR images with representative measurements at atrial end-diastole. (A) Two-chamber (2 Ch) view with left atrial (LA) length measurement. (B) Apical four-chamber (4 Ch) view with LA and right atrial (RA) 4 Ch length measurement. (C) 2 Ch view with LA endocardial border tracings. (D) $4 \mathrm{Ch}$ view with LA and RA endocardial border tracings. P: Posterior. L: Left.

30]. Enlarged CMR volume index was defined to be $\geq 55$ $\mathrm{ml} / \mathrm{m}^{2}$, two standard deviations (SD) above the mean of normal, healthy subjects in published population studies [31-36]. CMR analyses were performed by two experienced observers (CWT, TDO) blinded to other results.

\section{Statistical analysis}

Continuous data are presented as mean \pm SD. Categorical data are presented as counts and percentages. The difference in continuous measures between subject subgroups was assessed using Student's t test. The difference in categorical measures between subject subgroups and the prevalence of $\mathrm{AE}$ among the subject subgroups were assessed using Fisher's exact test. Sensitivity, specificity, positive predictive value (PPV) and negative predictive value (NPV) were used to assess the test performance for ECG
LAE and RAE. The accuracy of ECG LAE and RAE were computed individually and in combination. The independent relationships of hypertension and CMR LAE to ECG LAE were further evaluated with logistic regression. A p-value of $\leq 0.05$ was considered statistically significant. All statistical analyses were performed using SAS for Windows (v.9.1, SAS Institute, Cary, NC).

\section{Results}

\section{Study population}

The 275 study subjects consisted of 184 (67\%) males, 91 females (age $51 \pm 14$ years; range 18 to 83 years) who were consecutively referred for clinical or research CMR study, including $27 \%$ subjects with a history of $\mathrm{AF}$ and $34 \%$ with a history of hypertension. For the entire group, CMR LA and RA volumes were $97 \pm 38 \mathrm{ml}$ and $79 \pm 32 \mathrm{ml}$, respec- 
tively, and LA and RA volume indices were $49 \pm 17 \mathrm{ml} / \mathrm{m}^{2}$ and $40 \pm 15 \mathrm{ml} / \mathrm{m}^{2}$, respectively. The prevalence of CMR $\mathrm{AE}$ and ECG AE is presented in Table 1. Normotensive subjects and those with a history of hypertension had a similar prevalence of CMR LAE (30\%, p = 1.0). Compared to subjects in sinus rhythm, subjects with a history of AF had a significantly higher prevalence of CMR LAE and but not CMR RAE (Figure 2).

\section{Accuracy of ECG for anatomic atrial enlargement}

The accuracy of ECG LAE is presented in Table 2. The presence of at least one ECG LAE criteria had a sensitivity of $90 \%$ with a NPV of $84 \%$ and specificity of $21 \%$ for detection of CMR LAE. When ECG criteria were analyzed independently, $\mathrm{P}$ wave $>0.11 \mathrm{~s}$ offered the highest sensitivity for CMR LAE, with a NPV of $85 \%$. Three individual ECG criteria were very specific for detecting CMR LAE. The presence of $\mathrm{P}$ mitrale, $\mathrm{P}$ wave axis $<30^{\circ}$, and NPTF-V1 $>$ $0.04 \mathrm{~s} \cdot \mathrm{mm}$ were $99 \%, 90 \%$, and $88 \%$ specific, respectively, for detecting CMR LAE, although these criteria were not sensitive. The presence of P mitrale had a high PPV of $86 \%$ for CMR LAE.

The ECG was insensitive but highly specific for CMR RAE (Table 2). The presence of P wave in leads II, III, or aVF > $2.5 \mathrm{~mm}$ or positive $\mathrm{P}$ wave in $\mathrm{V} 1>1.5 \mathrm{~mm}$ had specificities of $100 \%$ and $96 \%$, respectively, for diagnosing CMR RAE. Both criteria had a NPV of $90 \%$, indicating low rates of false-negative results.

\section{Association of hypertension with ECG LAE}

Because hypertension may affect $P$ wave characteristics on ECG independently of atrial size [37], we performed logistic regression to assess the independent relationships of

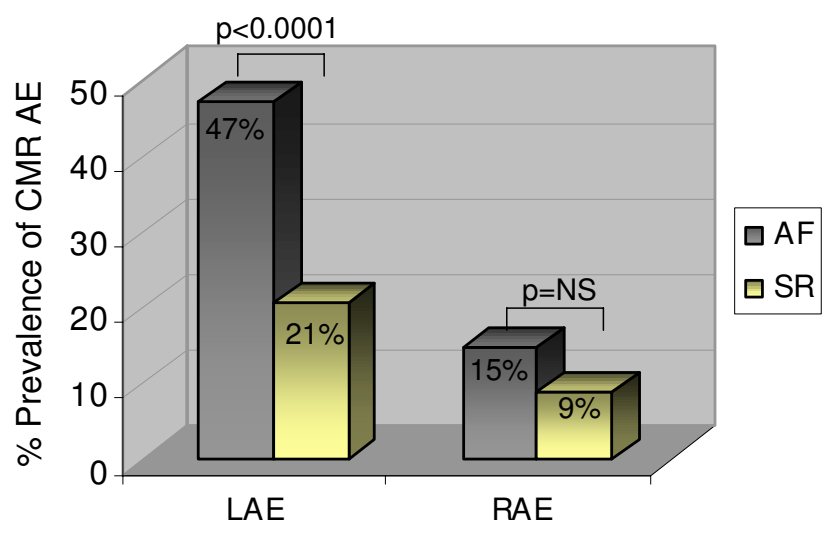

\section{Figure 2}

Prevalence of CMR atrial enlargement (AE) among subjects in sinus rhythm (SR) and with atrial fibrillation (AF). Subjects with AF have a significantly higher prevalence of left (LAE) but not right atrial enlargement (RAE), compared with subjects in SR. hypertension and CMR LAE to ECG LAE. With simultaneous adjustment, only CMR LAE, and not the presence of hypertension, was significantly associated with ECG LAE (OR 2.9, 95\% CI 1.2 to $7.3, \mathrm{p}=0.023$ ).

\section{Discussion}

The commonly used ECG criteria for atrial enlargement have been compared to anatomic atrial size by M-mode or 2-D echocardiography [15-23,38], which have inherent disadvantages including limited acoustic windows and spatial resolution, geometric assumptions made for estimation of atrial size, and moderate interobserver variability of measurements. The goal of this study was to characterize the accuracy of commonly used ECG atrial enlargement criteria against a gold standard of volumetric CMR measurements.

The presence of any ECG LAE criteria was 90\% sensitive with a NPV of $84 \%$, but had poor specificity of only $21 \%$ for CMR LAE. Using a combination of ECG LAE criteria is thus highly sensitive for detection of anatomic LAE, with a low false negative rate. This study indicates that commonly used ECG LAE criteria are more sensitive for anatomic LAE than the 6-69\% sensitivity previously reported using echocardiographic standards $[16,18,22,23,38]$. The criteria of $\mathrm{P}$ mitrale, $\mathrm{P}$ wave axis $<30^{\circ}$, and terminal $\mathrm{P}$ wave in $\mathrm{V} 1>0.04 \mathrm{~s} \cdot \mathrm{mm}$ were each highly specific although not sensitive for CMR LAE. In our CMR study, we found higher specificities of $P$ mitrale and terminal $P$ wave in $\mathrm{V} 1>0.04 \mathrm{~s} \cdot \mathrm{mm}$ for anatomic LAE than those obtained by similar atrial bi-plane volume analysis using 2-D echocardiography [38]. In addition, the high specificity of the criteria of $\mathrm{P}$ wave axis $<30^{\circ}$ to detect LAE has not been previously described to our knowledge. Compared with prior M-mode echocardiographic studies $[16,18,23,25]$, we found higher sensitivity but lower specificity for $\mathrm{P}>0.11 \mathrm{~s}$, and similar excellent specificity for $\mathrm{P}$ mitrale and NPTF-V1 $>0.04 \mathrm{~s} \cdot \mathrm{mm}$ to detect CMR LAE. The overall increased sensitivity of ECG LAE compared to ECG RAE may be explained by a larger number of criteria used, as well as high prevalence of the very sensitive criteria $P>0.11$ s.

Our results indicate that ECG criteria are insensitive but highly specific to detect CMR RAE, and are in agreement with analyses using echocardiographic volumetric RAE [39]. We found similar sensitivity but greatly improved specificity and both positive and negative predictive values of ECG for CMR RAE compared to 2-D echocardiographic standards [40]. No individual ECG criteria had both high sensitivity and specificity for predicting anatomic RAE. Though many of the commonly used individual ECG LAE and RAE criteria have high specificity for anatomic $\mathrm{AE}$, their prevalence is rare even in our referral population. 
Table I: Prevalence of Atrial Enlargement by CMR and ECG

\begin{tabular}{|c|c|c|c|}
\hline LAE & & RAE & \\
\hline \multicolumn{4}{|c|}{ CMR Criteria } \\
\hline Volume index $\geq 55 \mathrm{ml} / \mathrm{m}^{2}$ & $28 \%$ & Volume index $\geq 55 \mathrm{ml} / \mathrm{m}^{2}$ & $11 \%$ \\
\hline \multicolumn{4}{|c|}{ ECG Criteria } \\
\hline Any ECG criteria for LAE & $82 \%$ & Any ECG criteria for RAE & $5 \%$ \\
\hline$P>0.1 \mathrm{Is}$ & $70 \%$ & Inferior $P$ waves $>2.5 \mathrm{~mm}$ & $1 \%$ \\
\hline P mitrale & $3 \%$ & Positive $P$ wave in $V I>1.5 \mathrm{~mm}$ & $4 \%$ \\
\hline$P$ axis $<30^{\circ}$ & $9 \%$ & & \\
\hline NPTF-VI > 0.04s $\cdot \mathrm{mm}$ & $16 \%$ & & \\
\hline PPTF-aVL > $0.5 \mathrm{~mm}$ & $41 \%$ & & \\
\hline
\end{tabular}

CMR: Cardiovascular magnetic resonance. ECG: Electrocardiography. LAE: Left atrial enlargement. RAE: Right atrial enlargement. P mitrale: Notched $\mathrm{P}$ wave with interpeak duration $>0.04 \mathrm{~s}$. NPTF-VI $>0.04 \mathrm{~s} \cdot \mathrm{mm}$ : Area of negative $\mathrm{P}$ terminal force in lead VI $>0.04 \mathrm{~s} \cdot \mathrm{mm}$. PPTF-aVL: Positive $P$ terminal force in lead aVL. Inferior $P$ waves: $P$ wave in any of the leads II, III, or aVF.

Our CMR measurements are in agreement with Anderson et al [41], who reported higher CMR normative upper reference range atrial dimensions compared to echocardiographic standards. Though our mean volume indices exceed normative values by the American Society of Echocardiography [42], CMR volumetric measures have been shown to exceed that of echocardiography by 14$37 \%[41,43]$. CMR measurements in this study are consistent with those obtained in past CMR studies [29,32$36]$, which published upper limits of normative LA volumes ranging $50-69 \mathrm{ml} / \mathrm{m}^{2}$. Within CMR studies, there is a range of volumes reported in healthy subjects, with smaller volumes found in studies with younger, as opposed to middle-aged, subjects [36,44,45].
Abnormalties in atrial conduction resulting from hypertension, elevated pulmonary capillary wedge pressure, or intrinsic conduction defects are associated with abnormalities in the P wave $[37,46,47]$ and may be independent of atrial size. Thus, it is not surprising that in our study, ECG LAE criteria were sensitive but not specific. Since multiple etiologies may account for similar conduction disturbances in the $\mathrm{P}$ wave, the manifestation of such ECG criteria may be more accurately described as indicating atrial "abnormality" rather than "enlargement".

In logistic regression analysis, we demonstrated that CMR LAE was associated with ECG LAE independently of hypertension. However, a limitation of our study was that

Table 2: Accuracy of ECG criteria for Left and Right Atrial Enlargement as Detected by CMR

\begin{tabular}{|c|c|c|c|c|}
\hline ECG Criteria & Sensitivity (\%) & Specificity (\%) & PPV (\%) & NPV (\%) \\
\hline \multicolumn{5}{|c|}{ LAE } \\
\hline Any ECG Criteria for LAE & 90 & 21 & 31 & 84 \\
\hline$P>0.1 \mathrm{ls}$ & 84 & 35 & 34 & 85 \\
\hline P mitrale & 8 & 99 & 86 & 74 \\
\hline$P$ axis $<30^{\circ}$ & 8 & 90 & 23 & 71 \\
\hline NPTF-VI > 0.04s·mm & 37 & 88 & 47 & 76 \\
\hline PPTF-aVL > $0.5 \mathrm{~mm}$ & 44 & 60 & 30 & 73 \\
\hline \multicolumn{5}{|c|}{ RAE } \\
\hline Any ECG Criteria for RAE & 17 & 96 & 33 & 91 \\
\hline Inferior $P$ waves $>2.5 \mathrm{~mm}$ & 7 & 100 & 67 & 90 \\
\hline Positive $P$ wave in $\mathrm{VI}>1.5 \mathrm{~mm}$ & 10 & 96 & 25 & 90 \\
\hline
\end{tabular}

CMR: Cardiovascular magnetic resonance. ECG: Electrocardiography. PPV: Positive predictive value. NPV: Negative predictive value. LAE: Left atrial enlargement. RAE: Right atrial enlargement. $P$ mitrale: Notched $P$ wave with interpeak duration $>0.04 \mathrm{~s}$. NPTF-VI $>0.04 \mathrm{~s} \cdot \mathrm{mm}$ : Area of negative $P$ terminal force in lead VI $>0.04 \mathrm{~s} \cdot \mathrm{mm}$. PPTF-aVL: Positive P terminal force in lead aVL. Inferior P waves: P wave in any of the leads II, III, or aVF. 
we were not able to adjust for other factors which may affect $\mathrm{P}$ wave morphology, such as the use of sodium channel blocking medications, as this information was unavailable. In addition, since this study was noninvasive, we were not able to measure atrial pressures, which may also affect the P wave [46].

\section{Conclusion}

Our results further validate the strengths and weaknesses of commonly used ECG LAE and RAE criteria against the gold standard of anatomic measurements. Compared with volumetric CMR measures, none of the commonly used ECG LAE or RAE criteria provided high accuracy for detecting anatomic LAE or RAE. High sensitivity was achieved only with lower specificity and vice versa. The presence of any ECG LAE criteria and the individual criterion of $\mathrm{P}>0.11$ s were highly sensitive for CMR LAE, while the criteria $\mathrm{P}$ mitrale, $\mathrm{P}$ wave axis $<30^{\circ}$, and NPTF-V1 $>$ $0.04 \mathrm{~s} \cdot \mathrm{mm}$ were very specific, though poorly sensitive, for detecting CMR LAE. ECG RAE criteria were highly specific, though insensitive, for detecting anatomic RAE. The limited specificity of the most sensitive ECG criteria for anatomic atrial enlargement is consistent with the fact that $\mathrm{P}$ wave perturbations reflect changes in atrial conduction, which may be due to a variety of etiologies. Thus, the term atrial "abnormality" may be more appropriate than "enlargement" to describe such ECG findings.

\section{Competing interests}

The author(s) declare that they have no competing interests.

\section{References}

I. Tsang TS, Barnes ME, Gersh BJ, Bailey KR, Seward JB: Left atrial volume as a morphophysiologic expression of left ventricular diastolic dysfunction and relation to cardiovascular risk burden. Am J Cardiol 2002, 90( ( 2): 1284-9.

2. Alsaileek AA, Osranek M, Fatema K, McCully RB, Tsang TS, Seward JB: Predictive value of normal left atrial volume in stress echocardiography. J Am Coll Cardiol 2006, 47(5): 1024-8.

3. Altunkeser BB, Ozdemir K, Gok H, Temizhan A, Tokac M, Karabag $\mathrm{T}$ : Can $\mathbf{P}$ wave parameters obtained from I2-lead surface electrocardiogram be a predictor for atrial fibrillation in patients who have structural heart disease? Angiology 2003, 54(4):475-9.

4. Gerdts E, Oikarinen L, Palmieri V, Otterstad JE, Wachtell K, Boman $\mathrm{K}$, Dahlof $B$, Devereux RB: Correlates of left atrial size in hypertensive patients with left ventricular hypertrophy: the Losartan Intervention For Endpoint Reduction in Hypertension (LIFE) Study. Hypertension 2002, 39(3):739-43.

5. Tsang TS, Barnes ME, Bailey KR, Leibson CL, Montgomery SC, Takemoto Y, Diamond PM, Marra MA, Gersh BJ, Wiebers DO, Petty GW, Seward JB: Left atrial volume: important risk marker of incident atrial fibrillation in 1655 older men and women. Mayo Clin Proc 200I, 76(5):467-75.

6. Tsang TS, Barnes ME, Gersh BJ, Bailey KR, Seward JB: Risks for atrial fibrillation and congestive heart failure in patients $>l=$ 65 years of age with abnormal left ventricular diastolic relaxation. Am J Cardiol 2004, 93(1):54-8.

7. Barnes ME, Miyasaka Y, Seward JB, Gersh BJ, Rosales AG, Bailey KR, Petty GW, Weibers DO, Tsang TS: Left atrial volume in the prediction of first ischemic stroke in an elderly cohort without atrial fibrillation. Mayo Clin Proc 2004, 79(8): I008-I4.
8. Modena MG, Muia N, Sgura FA, Molinari R, Castella A, Rossi R: Left atrial size is the major predictor of cardiac death and overall clinical outcome in patients with dilated cardiomyopathy: a long-term follow-up study. Clin Cardiol 1997, 20(6):553-60.

9. Moller JE, Hillis GS, Oh JK, Seward JB, Reeder GS, Wright RS, Park SW, Bailey KR, Pellikka PA: Left atrial volume: a powerful predictor of survival after acute myocardial infarction. Circulation 2003, 107(17):2207-12.

10. Tsang TS, Abhayaratna WP, Barnes ME, Miyasaka Y, Gersh BJ, Bailey KR, Cha SS, Seward JB: Prediction of cardiovascular outcomes with left atrial size: is volume superior to area or diameter? J Am Coll Cardiol 2006, 47(5): 1018-23.

II. Verma A, Anavekar NS, Meris A, Thune JJ, Arnold JM, Ghali JK, Velazquez EJ, McMurray JJ, Pfeffer MA, Solomon SD: The relationship between renal function and cardiac structure, function, and prognosis after myocardial infarction: the VALIANT Echo Study. J Am Coll Cardiol 2007, 50(1 3): 1238-45.

12. Tsang TS, Barnes ME, Gersh BJ, Takemoto Y, Rosales AG, Bailey KR, Seward JB: Prediction of risk for first age-related cardiovascular events in an elderly population: the incremental value of echocardiography. J Am Coll Cardiol 2003, 42(7): I 199-205.

13. Fonseca C, Mota T, Morais H, Matias F, Costa C, Oliveira AG, Ceia $F$ : The value of the electrocardiogram and chest $X$-ray for confirming or refuting a suspected diagnosis of heart failure in the community. Eur J Heart Fail 2004, 6(6):807-12. 82I-2

14. Raymond RJ, Hinderliter AL, Willis PW, Ralph D, Caldwell EJ, Williams W, Ettinger NA, Hill NS, Summer WR, de Boisblanc B, Schwartz T, Koch G, Clayton LM, Jobsis MM, Crow JW, Long W: Echocardiographic predictors of adverse outcomes in primary pulmonary hypertension. J Am Coll Cardiol 2002, 39(7): 1214-9.

15. Chirife R, Feitosa GS, FrankI WS: Electrocardiographic detection of left atrial enlargement. Correlation of $P$ wave with left atrial dimension by echocardiography. Br Heart J 1975, 37( 12$): 128 \mid-5$.

16. Hazen MS, Marwick TH: Underwood DA. Diagnostic accuracy of the resting electrocardiogram in detection and estimation of left atrial enlargement: an echocardiographic correlation in $55 \mathrm{I}$ patients. Am Heart J I99I, I 22(3 Pt I):823-8.

17. Hopkins $C B$, Barrett $O$ Jr: Electrocardiographic diagnosis of left atrial enlargement. Role of the $P$ terminal force in lead $V I$. J Electrocardiol 1989, 22(4):359-63.

18. Munuswamy K, Alpert MA, Martin RH, Whiting RB, Mechlin NJ: Sensitivity and specificity of commonly used electrocardiographic criteria for left atrial enlargement determined by $M$ mode echocardiography. Am / Cardiol I984, 53(6):829-32.

19. Perosio AM, Suarez LD, Torino A, Llera JJ, Ballester A, Roisinblit JM: Reassessment of electrovectorcardiographic signs of left atrial enlargement. Clin Cardiol 1982, 5(I 2):640-6.

20. Reeves WC: ECG criteria for right atrial enlargement. Arch Intern Med I983, I 43(II):2I55-6.

21. Rubler S, Shah NN, Moallem A: Comparison of left atrial size and pulmonary capillary pressure with $\mathbf{P}$ wave of electrocardiogram. Am Heart J 1976, 92(I):73-8.

22. van Dam I, Roelandt J, Robles de Medina EO: Left atrial enlargement: an electrocardiographic misnomer? An electrocardiographic-echocardiographic study. Eur Heart J 1986, 7(2): I I5-7.

23. Waggoner $A D$, Adyanthaya $A V$, Quinones MA, Alexander JK: Left atrial enlargement. Echocardiographic assessment of electrocardiographic criteria. Circulation 1976, 54(4):553-7.

24. Lester SJ, Ryan EW, Schiller NB, Foster E: Best method in clinical practice and in research studies to determine left atrial size. Am J Cardiol 1999, 84(7):829-32.

25. Ikram H, Drysdale P, Bones PJ, Chan W: The non-invasive recognition of left atrial enlargement: comparison of electro- and echocardiographic measurements. Postgrad Med J 1977, 53(62I):356-9.

26. Chou TC: Atrial abnormalities. In Electrocardiography in Clinical Practice. In Electrocardiography in Clinical Practice 3rd edition. Edited by: Chou TC. Philadelphia: W.B. Saunders; 1991:29-35.

27. Friedman $\mathrm{H}$ : Atrial abnormalities. In Diagnostic Electrocardiography and Vectorcardiography 3rd edition. New York: McGraw-Hill; 1985.

28. Lang RM, Bierig M, Devereux RB, Flachskampf FA, Foster E, Pellikka PA, Picard MH, Roman MJ, Seward J, Shanewise JS, Solomon SD, Spencer KT, Sutton MS, Stewart WJ: Recommendations for chamber quantification: a report from the American Society of Echocardiography's Guidelines and Standards Committee 
and the Chamber Quantification Writing Group, developed in conjunction with the European Association of Echocardiography, a branch of the European Society of Cardiology. I Am Soc Echocardiogr 2005, I 8(I 2): 1440-63.

29. Hudsmith LE, Petersen SE, Francis JM, Robson MD, Neubauer S: Normal human left and right ventricular and left atrial dimensions using steady state free precession magnetic resonance imaging. J Cardiovasc Magn Reson 2005, 7(5):775-82.

30. Sievers B, Kirchberg S, Addo M, Bakan A, Brandts B, Trappe HJ: Assessment of left atrial volumes in sinus rhythm and atrial fibrillation using the biplane area-length method and cardiovascular magnetic resonance imaging with TrueFISP. J Cardiovasc Magn Reson 2004, 6(4):855-63.

31. Jarvinen VM, Kupari MM, Hekali PE, Poutanen VP: Right atrial MR imaging studies of cadaveric atrial casts and comparison with right and left atrial volumes and function in healthy subjects. Radiology 1994, 191 (I):137-42.

32. Jarvinen VM, Kupari MM, Poutanen VP, Hekali PE: Right and left atrial phasic volumetric function in mildly symptomatic dilated and hypertrophic cardiomyopathy: cine MR imaging assessment. Radiology 1996, 198(2):487-95.

33. Jarvinen VM, Kupari MM, Poutanen VP, Hekali PE: A simplified method for the determination of left atrial size and function using cine magnetic resonance imaging. Magn Reson Imaging 1996, I4(3):215-26.

34. Therkelsen SK, Groenning BA, Svendsen JH, Jensen GB: Atrial and ventricular volume and function in persistent and permanent atrial fibrillation, a magnetic resonance imaging study. J Cardiovasc Magn Reson 2005, 7(2):465-73.

35. Therkelsen SK, Groenning BA, Svendsen JH, Jensen GB: Atrial and ventricular volume and function evaluated by magnetic resonance imaging in patients with persistent atrial fibrillation before and after cardioversion. Am J Cardiol 2006, 97(8): I 2 I3-9.

36. Tseng WY, Liao TY, Wang JL: Normal systolic and diastolic functions of the left ventricle and left atrium by cine magnetic resonance imaging. J Cardiovasc Magn Reson 2002, 4(4):443-57.

37. Di Bianco R, Gottdiener JS, Fletcher RD, Pipberger HV: Left atrial overload: a hemodynamic, echocardiographic, electrocardiographic and vectorcardiographic study. Am Heart J 1979, 98(4):478-89.

38. Lee KS, Appleton CP, Lester SJ, Adam TJ, Hurst RT, Moreno CA, Altemose GT: Relation of electrocardiographic criteria for left atrial enlargement to two-dimensional echocardiographic left atrial volume measurements. Am J Cardiol 2007, 99(I): I I3-8.

39. Kaplan JD, Evans GT Jr, Foster E, Lim D, Schiller NB: Evaluation of electrocardiographic criteria for right atrial enlargement by quantitative two-dimensional echocardiography. J Am Coll Cardiol 1994, 23(3):747-52.

40. Reeves WC, Hallahan W, Schwiter El, Ciotola T): Buonocore E, Davidson W. Two-dimensional echocardiographic assessment of electrocardiographic criteria for right atrial enlargement. Circulation 1981, 64(2):387-91.

4I. Anderson JL, Horne BD, Pennell DJ: Atrial dimensions in health and left ventricular disease using cardiovascular magnetic resonance. J Cardiovasc Magn Reson 2005, 7(4):67I-5.

42. Lang RM, Bierig M, Devereux RB, Flachskampf FA, Foster E, Pellikka PA, Picard MH, Roman MJ, Seward J, Shanewise J, Solomon S, Spencer KT, St John Sutton M, Stewart W: Recommendations for chamber quantification. Eur J Echocardiogr 2006, 7(2):79-108.

43. Rodevan O, Bjornerheim R, Ljosland M, Maehle J, Smith HJ, Ihlen $\mathrm{H}$ : Left atrial volumes assessed by three- and two-dimensional echocardiography compared to MRI estimates. Int J Card Imaging 1999, I 5(5):397-4I0.

44. Poutanen $T$, Jokinen $E$, Sairanen $H$, Tikanoja $T$ : Left atrial and left ventricular function in healthy children and young adults assessed by three dimensional echocardiography. Heart 2003 , 89(5):544-9.

45. Raman SV, Ng VY, Neff MA, Sayar S, Sparks EA, Nelson SD, Ferketich AK, Wooley CF: Volumetric cine CMR to quantify atrial structure and function in patients with atrial dysrhythmias. J Cardiovasc Magn Reson 2005, 7(3):539-43.

46. Josephson ME, Kastor JA, Morganroth J: Electrocardiographic left atrial enlargement. Electrophysiologic, echocardiographic and hemodynamic correlates. Am J Cardiol I977, 39(7):967-7I.
47. Saunders JL, Calatayud JB, Schulz KJ, Maranhao V, Gooch AS, Goldberg $\mathrm{H}$ : Evaluation of ECG criteria for $\mathbf{P}$-wave abnormalities. Am Heart J 1967, 74(6):757-65.
Publish with Biomed Central and every scientist can read your work free of charge

"BioMed Central will be the most significant development for disseminating the results of biomedical research in our lifetime. "

Sir Paul Nurse, Cancer Research UK

Your research papers will be:

- available free of charge to the entire biomedical community

- peer reviewed and published immediately upon acceptance

- cited in PubMed and archived on PubMed Central

- yours - you keep the copyright 